\title{
Analysis on the Regional Structure of Global Natural Gas Consumption Zhang-huang $\mathrm{YE}^{1,2}$ and Qiang $\mathrm{YAN}^{2}$
}

1.Jiangxi Science and Technology Normal University, Nanchang, Jiangxi; 2.Institute of Mineral Resources, Chinese Academy of Geological Sciences, Beijing;

Keywords: Natural gas; consumption; region; economic development

\begin{abstract}
In 2015, the total consumption of global natural gas is 3.47 trillion cubic meters. It is predicted that natural gas will be "the largest energy" among the whole energy consumption before 2040. According to the regional structure of natural gas consumption, the gas natural consumption of none-OECD countries begins to exceed the consumption of OECD countries in 2007, and the gap has a tendency to increase year by year especially in Brazil, Russia, India, and China. Nevertheless, the per capita consumption of natural gas in OECD is 5.2 times of Non-OECD. The natural gas consumption in Asia-Pacific region is increasing rapidly, which is expected to be the center of natural gas consumption since Europe and America. From the per capita consumption, the consumption in the region with rich natural gas resources such as North America, the Middle East and former Soviet Union is more than 2 tons of oil equivalent, and the consumption in many economic less-developed regions of Asia-Africa-Latin America is below 0.5 ton of oil equivalent. If resources are the main constraint on natural gas production pattern, the consumption pattern is influenced by the demand of economic development.

The total global natural gas consumption in 2015 is 3.47 trillion cubic meters. Natural gas not only has a steady-state growth in the aspect of overall consumption, but also presents a rising proportion in the consumption structure of primary energy with each passing year. Natural gas, it is predicted, will become "the largest energy" among the whole energy consumption before 2040 (Scott, 2012; Tong, 2010). However, regional structures of its consumption vary widely, and it has significance to have an analysis on it.
\end{abstract}

\section{Group of Developed Countries and Group of Developing Countries}

According to the region divided from the degree of economic development, natural gas consumption in OECD countries is on the rise, and its consumption is from 500 billion cubic meters in 1965 to 1.62 trillion cubic meters in 2015, which has increased 3.25 times with the annual growth rate of $2.5 \%$. The natural gas consumption in none-OECD countries is much more faster, and its consumption is from 150 billion cubic meters in 1965 to 1.86 trillion cubic meters in 2015, which has increased 12.1 times with the annual growth rate of 5.3\%. Obviously, the increase of natural gas consumption in ODCD is far less than that of in none-ODCD. In 2007, the consumption of none-ODCD begins to exceed the consumption of OECD, and the gap has a tendency to increase year by year (Fig. 1). In recent years, the main reason for small increase of natural gas consumption is the depressed consumption of European Union, the main part of OECD, even arising negative growth.

From 1965 to 2015, the proportion of natural gas consumption in OECD and none-OECD (Fig.1) presents some kinds of "scissors-shaped", and the gap is narrowing. The proportion of natural gas consumption in OECD has declined, which is from $76.4 \%$ in 1965 to $46.5 \%$ in 2015, and the proportion of natural gas consumption in none-OECD countries has climbed to $53.5 \%$ in 2015 from 23.6\% in 1965. Nevertheless, the gap is widening again in the early 1990s (The US-led western countries create a "new economy" era because of their robust economic development). Then, the gap is narrowing again presenting a "pod-shaped”.

However, from the consumption per capita in these two groups of countries, the natural gas consumption per capita in OECD is 1160 cubic meters in 2015, the consumption per capita in none OECD is only 220 cubic meters (population data sources: the official website of OECD), and the 
former is 5.2 times of the latter.
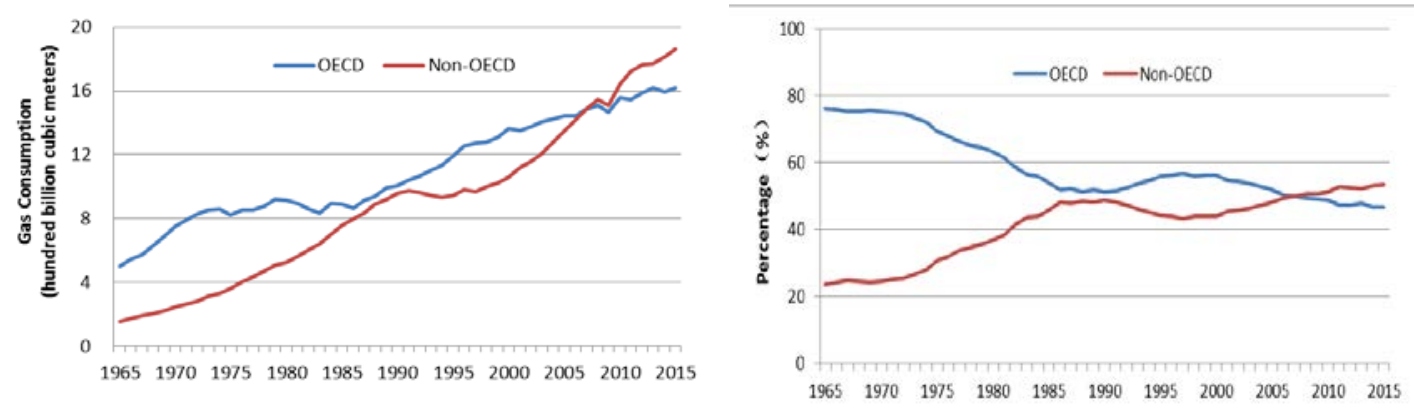

Figure 1. The Consumption of Natural Gas Consumption in OECD and

None-OECD from 1965 to 2015 (Data sources: BP, 2016)

\section{Developed Countries, the BRICs and Other Developing Countries}

The world can be divided into three groups of countries, OECD countries (representing developed countries or economics), the BRICs (representing emerging economics) and other countries (except for OECD countries and the BRICs). The natural gas consumption in these three groups is on the rise overall from 1965 to 2015. But the proportion of OECD countries has declined, the proportion of BRICs and other countries has increased continually (Note: the natural gas consumption of Russia from 1965 to 1984 is the ratio speculation based on the consumption of the former Soviet Union) (Fig. 2).
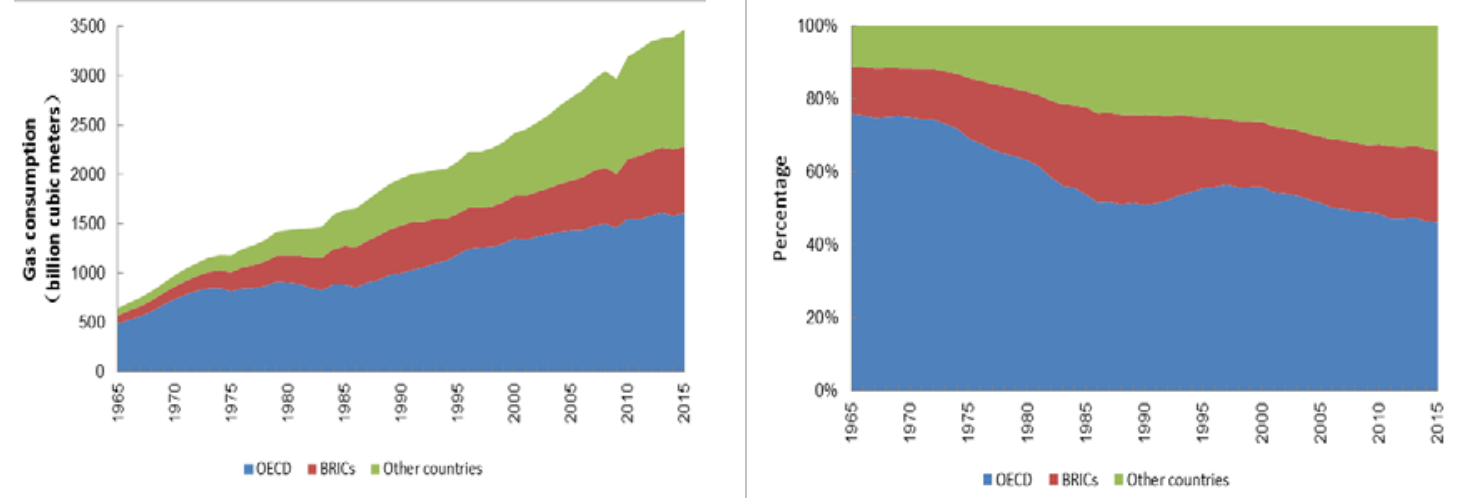

Fig. 2 .The Consumption of Natural Gas Consumption in OECD, BRICs and Other Countries from 1965 to 2015(Data sources: BP, 2016)

\section{Continents}

According to natural region, world can be divided into Europe (including Russia), North America, Central and South America, the Middle East, Africa, the Asia-Pacific, the six regional groups. In addition to the decline of North America in the early 1980s and Europe after 2008, the natural gas consumption in every regional group is overall on the rise from 1965 to 2015 (Fig. 3). Up to now, in addition to the natural gas consumption in Europe has peaked in 2008 (1.0335 trillion cubic meters), the consumption in other regional groups all has peaked in 2015. The natural gas consumption in Europe reaches 655.9 billion cubic meters in 1981, which exceeds North America. The growth multiple of consumption in Africa, the Middle East, the Asia-Pacific, Central and South America, Europe and North America, the six regional groups, from 1965 to 2015 is 135.3, 131.5, $119.8,12.3,6.4$ and 2.1 respectively; the growth is $10.5 \%, 10.4 \%, 10.3 \%, 5.3 \%, 3.9 \%$ and $1.5 \%$ respectively; the increment is 134.5 billion, 486.5 billion, 695.3 billion, 160.1 billion, 847.5 billion and 499.8 billion cubic meters respectively. With the completion of the industrialization in the United States and Europe, economic growth has slowed down as well as the growth of the demand for natural gas. But the consumption is still large, the average annual consumption of natural gas in 
Europe, North America, the Asia-Pacific, the Middle East, Central and South America and Africa is 784.5 billion, 698 billion, 224.2 billion, 146.5 billion, 72.5 billion and 46.2 billion cubic meters respectively from 1965 to 2015. The average annual consumption in Europe and North America is 17 times and 15 times of Africa respectively, which is like the old saying "A lean camel is still bigger than a horse". After entering the 1990s, the economy in the Asia-Pacific region has developed rapidly, and the demand for natural gas and its consumption have been on the rise. The increment is large (The cumulative increment occupies the second in the world from 1965 to 1974 and exceeds Europe to take the first place from 1975 to 2015.). The Asia-Pacific region is the main power of natural gas consumption, which is expected to be the center of global natural gas consumption since Europe and America.

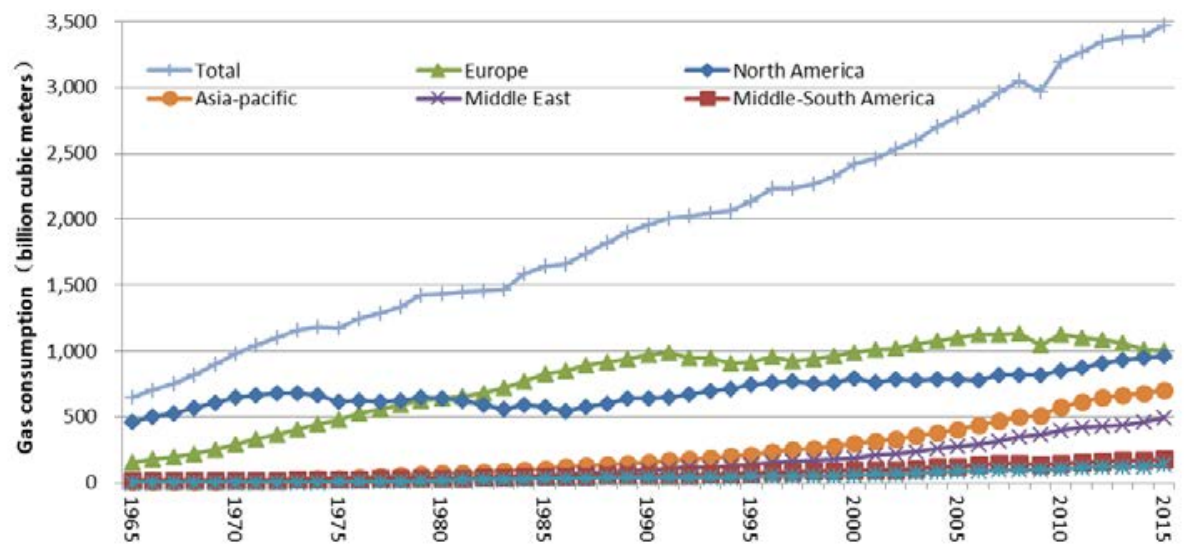

Fig 3. The Natural Gas Consumption in Different Continents from 1965 to 2015

(Data sources: BP, 2016)

The proportion of natural gas in different regional groups from 1965 to 2015 (Fig. 4) is more complicated. The proportion in North America has declined, which is from $72.7 \%$ in 1965 to $27.8 \%$ in 2015. The proportion in Europe has increased first and then decreased, which is $45.2 \%$ in 1981 , exceeding the $43.1 \%$ of North America. The proportion in other four regional groups continues to increase with the form of curve. But the proportion in the Asia-Pacific region is from $0.9 \%$ in 1965 to $20.2 \%$ in 2015, Central and South America from 2.2\% to 5.0\%, the Middle East from 0.6\% to $14.1 \%$, and Africa from $0.2 \%$ to $3.9 \%$. In 1973, the proportion in the Asia-Pacific region exceeds Central and South America, and the gap is larger and larger. These data also confirm that the development in the Asia-Pacific region is faster than the rest of the three regions, and its economic strength has been significantly improved. Therefore, there are closely positive correlations between natural gas consumption and economic development.

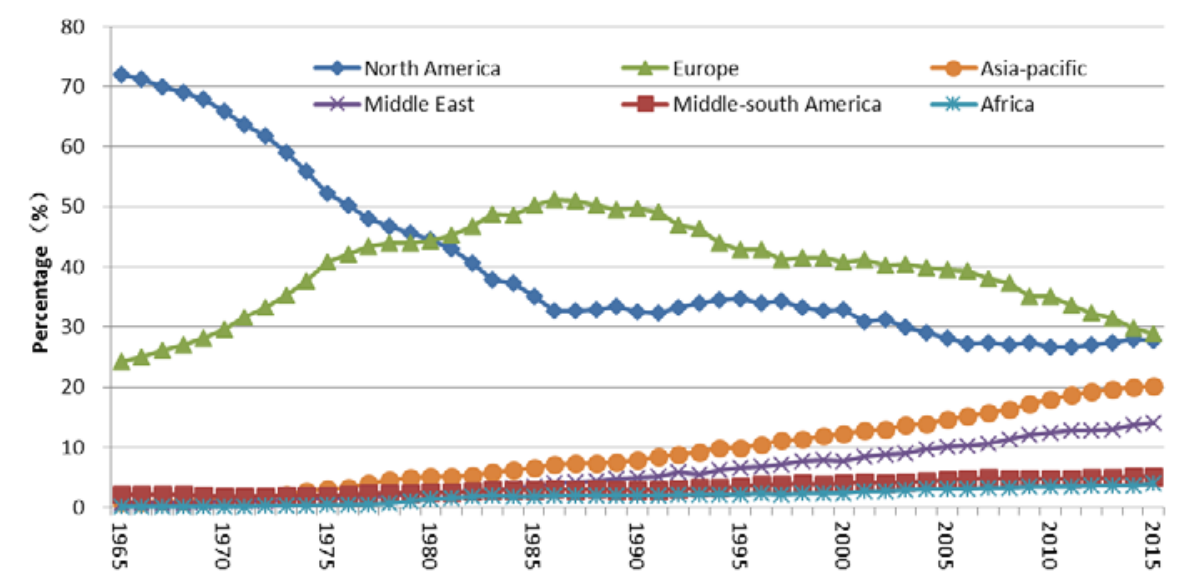

Fig. 4 Proportion of Natural Gas Consumption in Different Continents from 1965 to 2015

(Data sources: BP, 2016)

The natural gas consumption and proportion in different regional groups in 2015 are shown in 
Table 1. Among them, the natural gas consumption in Europe (including Russia) is the largest, which reaches 1.0035 trillion cubic meters, accounting for $28.9 \%$ of the global natural gas consumption. The consumption in North America is 963.6 billion cubic meters, accounting for $27.8 \%$, ranking the second. The consumption in the Asia-Pacific region is 678.6 billion cubic meters, accounting for $20.2 \%$, ranking the third. The consumption in the Middle East is 490.2 billion cubic meters, accounting for $14.1 \%$, ranking the fourth. The consumption in Central and South America is 174.8 billion cubic meters, accounting for $5.0 \%$, ranking the fifth. The consumption in Africa is 135.5 billion cubic meters, accounting for 3.9\%, ranking the last. Obviously, Europe and North America are two large centers of global natural gas consumption, and the total consumption in these two centers accounts for $56.7 \%$ of the global consumption.

Table 1 The Gas Consumption (100 million cubic meters) and Corresponding Proportion (\%) in Six Natural Regions in 2015(Data sources: BP, 2016)

\begin{tabular}{|c|c|c|c|c|c|c|c|}
\hline & Europe & $\begin{array}{c}\text { North } \\
\text { America }\end{array}$ & $\begin{array}{c}\text { Asia } \\
\text { Pacific }\end{array}$ & $\begin{array}{c}\text { Middle } \\
\text { East }\end{array}$ & $\begin{array}{c}\text { Central-South } \\
\text { America }\end{array}$ & Africa & Total \\
\hline Consumption & 10035 & 9636 & 6786 & 4902 & 1686 & 1233 & 33476 \\
\hline Proportion & 28.9 & 27.8 & 20.2 & 14.1 & 5.0 & 3.9 & 100.0 \\
\hline
\end{tabular}

\section{Countries}

According to the data released by BP (2016), the first twelve natural gas consumption powers are the United States, Russia, China, Iran, Japan, Canada, Saudi Arabia, Germany, Mexico, UK, United Arab Emirates and Italy, and their total consumption accounts for $64.5 \%$ of the global consumption. Among them, the United States and Russia are two consumption giants, whose consumption is 778 billion and 391.5 billion cubic meters respectively accounting for $22.4 \%$ and $11.3 \%$ respectively of the global consumption. The natural gas consumption of these two countries is more than one third of the world. According to the natural gas consumption and proportion from 1985 to 2015, these countries are traditional natural gas consumption powers, but the proportion of consumption has the tendency of decline (Fig 5).
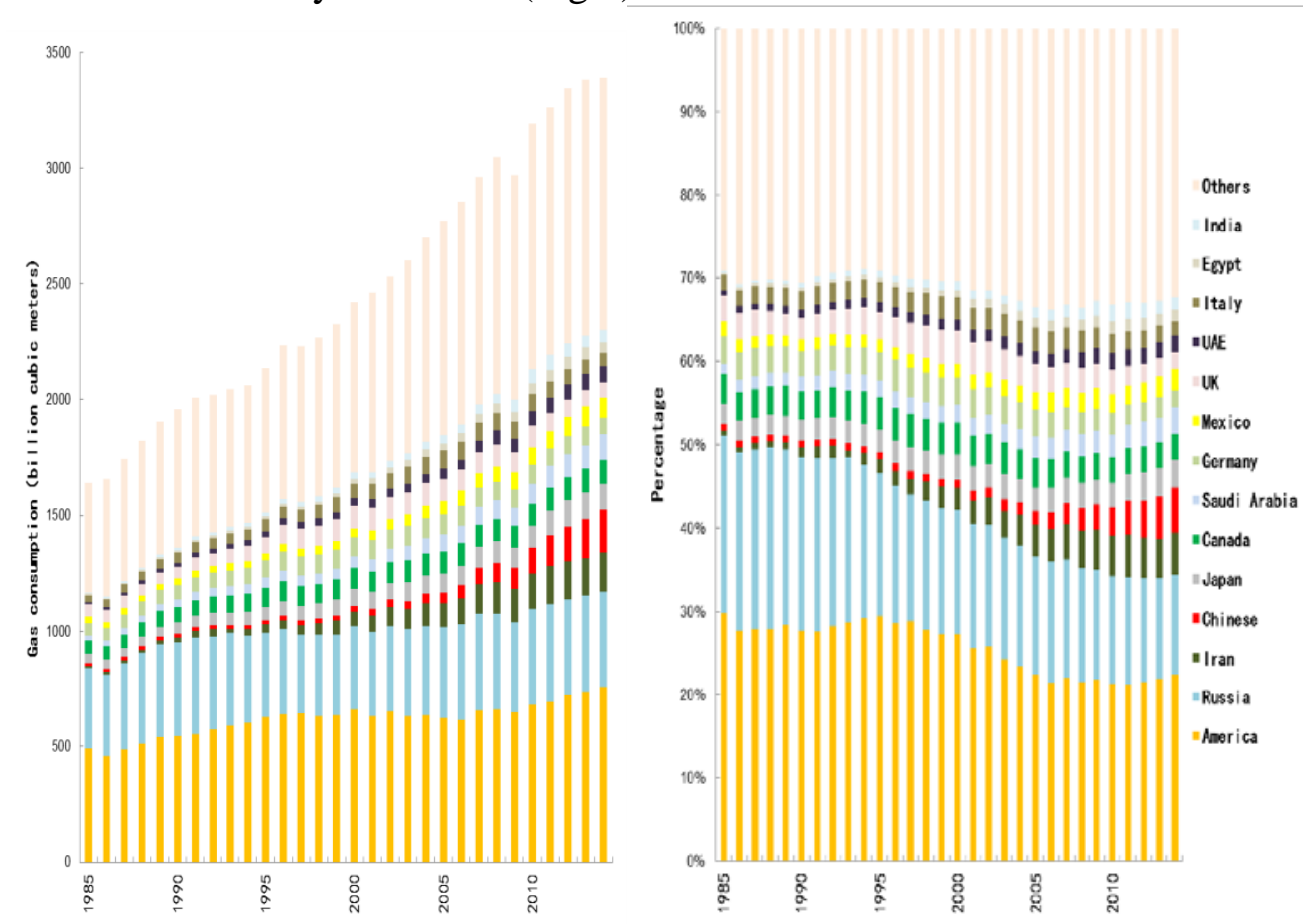

Fig. 5 The Main Gas Consumption countries from 1985 to 2015 (Data sources: BP, 2016) 


\section{Per Capita Consumption}

According to the consumption per capita, the natural gas consumption is concentrated in the region with abundant natural gas resources such as North America, the Middle East and the former Soviet Union, and their consumption per capita is over two tons of oil equivalent. Then, the consumption per capita in Europe, the Asia-Pacific region (mainly in Australia and a few countries in Southeast Asia) and some countries in Central and South America is 1 to 2 tons of oil equivalent. The consumption per capita in most underdeveloped regions such as Asia, Africa and Latin America is the lowest, which is below 0.5 ton of oil equivalent (Fig. 6).

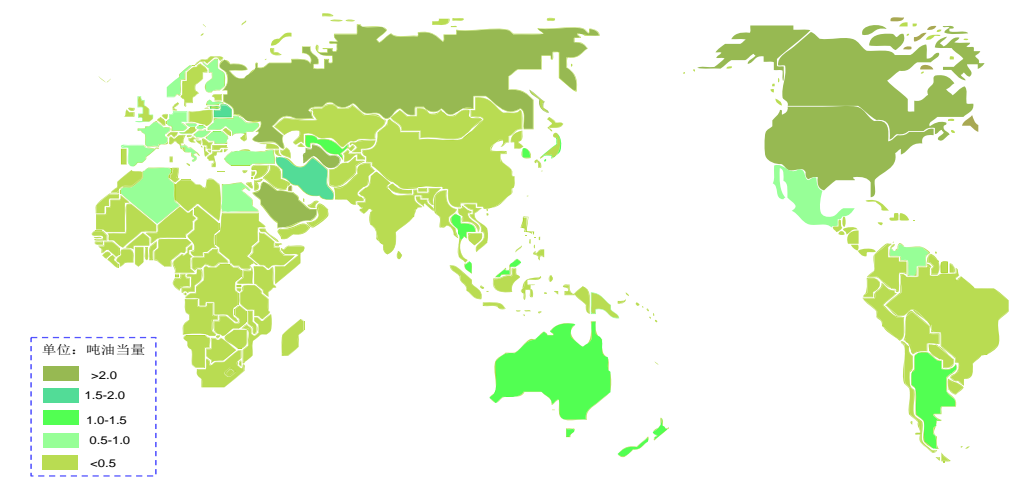

Fig. 6 The Distribution of Global Natural Gas Per Capita Consumption in 2015

(Data sources: BP, 2016)

\section{Conclusion}

The natural gas consumption in Asia-Pacific region is increasing rapidly, which is expected to be the center of natural gas consumption since Europe and America. If resources are the main constraint on natural gas production pattern, the consumption pattern is influenced by demands of economic development (Zhang, 2009; Zhou et al., 2009). According to the regional structure of natural gas consumption, comparing with other primary energy sources, natural gas industry has more characteristics of highly industrial integration over the upstream, midstream and downstream regions whose development degree is more obviously restricted by the level of economic development (Zhou et al., 2009).

\section{Reference}

[1]. Scott Montgomery. 2012. Trans. Song Yang, Jiang Wenbo. The Trend of Global Energy. Beijing: China Machine Press

[2]. Tong Xiaoguang. 2010. The Significance and Possibility of Fully Boosting the Proportion of Natural Gas in the Energy Mix. Natural Gas Industry (10)

[3]. Zhang Kang. 2009. The Geographic Peripheral Oil and Gas between China and the Rest of the World. Beijing: Geological Publishing House

[4]. Zhou Yuezhong, Li Ting. 2008. The Study of the Influence Factors on Consumption of Natural Gas. Market Modernization, (10): 187-188

[5]. Zhou Zhibin, Zhou Yipei. 2009. The Foundation, Prospect and Strategy of Coordinated Development on the Industry Chain of China's Natural Gas. Natural Gas Industry, (29) 